\title{
Gestão por resultados e a nova rotina escolar na rede municipal de ensino de Porto Alegre (RME/POA)
}

\author{
Results management and the new school routine in the municipal network of \\ education in Porto Alegre (RME / POA) \\ Gestión de resultados y la nueva rutina escolar en la red municipal de \\ educación de Porto Alegre (RME / POA)
}

\author{
CAROLINE PEREIRA LEAL \\ https://orcid.org/0000-0003-4633-8691 \\ Secretaria Municipal de Educação de Porto Alegre \\ Porto Alegre, RS, Brasil
}

\begin{abstract}
Resumo: O presente artigo discute a recente reforma na política em educação do município de Porto Alegre. Nosso objetivo é apresentar a nova rotina escolar implantada nas escolas da Rede Municipal de Ensino de Porto Alegre (RME/ POA), a partir de 2017, buscando descrever o processo reformista e discutir os instrumentos adotados pela administração municipal como forma de construção e de funcionamento da gestão por resultados aplicadas à educação. Quanto ao procedimento metodológico, foi realizada uma pesquisa documental, com a coleta de documentos oficiais e notícias jornalísticas a respeito da nova rotina escolar. Através de uma análise descritiva comparada, de abordagem qualitativa dos dados, foi possível verificar que a intervenção efetuada na realidade escolar gerou intensificação do trabalho docente e não se traduziu em efetividade e criação de valor público.
\end{abstract}

Palavras-chave: educação, reforma administrativa, gestão por resultados.

\begin{abstract}
This article discusses the recent reform in education policy in the city of Porto Alegre. Our goal is to present the new school routine implemented in schools of the Municipal Education Network of Porto Alegre (RME / POA), starting in 2017, seeking to describe the reform process and discuss the instruments adopted by the municipal administration as a way of construction and functioning results management applied to education As for the methodological procedure, documental research was carried out, with the collection of official documents and news about the new school routine. Through a comparative descriptive analysis, with a qualitative approach to the data, it was possible to establish that the intervention carried out in the school reality generated an intensification of the teaching work and did not translate into effectiveness and creation of public value.
\end{abstract}

Keywords: education, administrative reform, management by results. 
Resumen: Este articulo analiza la reciente reforma de la politica educativa en la ciudad de Porto Alegre. Nuestro objetivo es presentar la nueva rutina escolar implementada en las escuelas de la Red Municipal de Educación de Porto Alegre (RME / POA), a partir de 2017, buscando describir el proceso de reforma y discutir los instrumentos adoptados por la administración municipal como forma de construcción y funcionamiento. gestión de resultados aplicada a la educación. A través de la investigación documental, se consultaron documentos oficiales y noticias periodísticas sobre la nueva rutina escolar, que, mediante un análisis descriptivo comparativo, con un abordaje cualitativo de los datos, permitió constatar que la intervención realizada en la realidad escolar generó intensificación de la labor docente y no traducido en eficacia y creación de valor público.

Palabras clave: educación, reforma administrativa, gestión por resultados.

\section{INTRODUÇÃO}

O atual cenário da educação do município de Porto Alegre é marcado por uma reforma educacional levada a cabo, mais intensamente, a partir do governo Marchezan Júnior (PSDB), eleito prefeito da cidade no ano de 2016. Historicamente identificada como referência em uma educação crítica - orientada por ideais de uma gestão pública de caráter emancipatório, inclusivo e democrático - a partir de 2005, as políticas educacionais da Rede Municipal de Ensino de Porto Alegre (RME/POA) assumiram gradativamente orientações gerencialistas, que foram aprofundadas no comando da referida gestão (AGUIAR; SANTOS, 2018; AGUIAR, 2019).

Uma das primeiras ações da administração municipal foi o estabelecimento de uma nova rotina escolar, pautada na alteração dos horários das escolas e de uma série de ordenamentos que organizam o cotidiano escolar e que, de acordo com o secretário da educação, visavam "qualificar o tempo dos alunos na escola e com o professor” (PORTO ALEGRE, 2017c). Tais mudanças, desde o início de sua implantação, geraram um forte tensionamento entre a nova gestão da capital e os trabalhadores em educação do município de Porto Alegre (CHAGAS, 2017; PROFESSORES, 2017a). Desta forma, o presente artigo tem como objetivo apresentar a nova rotina escolar implantada nas escolas da RME/POA, buscando descrever o processo reformista e discutir os instrumentos adotados pela administração municipal como forma de construção e de funcionamento da gestão por resultados aplicada à educação. Cabe destacar que o processo reformista vai muito além de mudanças no dia a dia das escolas, trazendo transformações na concepção pedagógica da RME e que, embora a nova rotina tenha implicações no modo de se enxergar e executar o ensino na RME, este estudo se deteve apenas nas alterações normativas do cotidiano escolar advindas com o processo reformista. 
Em meados da década de 1980, defendendo a adoção do modelo gerencial e fazendo uso de instrumentos, ferramentas e metodologias de gestão da esfera privada, a Administração Pública adotou a Nova Gestão Pública como alternativa para se reestruturar e atender as demandas de uso eficiente do dinheiro público, de redução dos gastos com a máquina administrativa e maior qualidade na prestação dos serviços públicos. No Brasil, essa reforma administrativa de inspiração gerencial foi implantada a partir da década de 1990 e sua aplicação no setor educacional tem gerado controvérsias: de um lado aqueles que defendem a incorporação de princípios do setor privado ao setor público, ressignificando o conceito de qualidade dos serviços públicos, por meio da introdução da cultura empresarial, subsidiado pela concepção de planejamento estratégico; e de outro, aqueles que desenvolvem uma crítica ao modelo gerencial implantado na organização e na gestão dos sistemas educacionais, por recriminarem a inserção de ações que objetivam construir um Estado mínimo em termos de elaboração de políticas públicas sociais, em particular, na educação e por ser pautada pela lógica da lucratividade e competitividade (SOUZA; CABRAL NETO, 2017).

Em sua proposta de governo, Marchezan apresentou a gestão estratégica por resultados como o modelo que nortearia sua administração (PROGRAMA, 2016). A gestão por resultados é um modelo que segue um novo paradigma, no qual os fins se sobrepõem aos meios. Ao contrário de uma gestão tradicional, focada em processos, a gestão por resultados enfatiza os objetivos a serem alcançados e os valores da organização. $\mathrm{O}$ foco é priorizar os resultados em todas as ações, com o objetivo de otimizar o desempenho da organização.

Um marco conceitual cuja função é a de facilitar às organizações públicas a direção efetiva e integrada de seu processo de criação de valor público, a fim de otimizá-la, assegurando a máxima eficácia, eficiência e efetividade de desempenho, além da consecução dos objetivos de governo e a melhoria contínua de suas instituições (SERRA, 2008, p. 23).

Para que possa ser implementada, é necessária a construção de uma agenda estratégica - um conjunto de definições sobre os propósitos, sobre os resultados a serem alcançados e sobre como alcançá-los. É nesse sentido que Matias-Pereira (2009, p.144) apresenta a missão; o diagnóstico do ambiente; os objetivos estratégicos; os indicadores de desempenho; as metas de desempenho; o monitoramento de desempenho; e os planos de ação (que retroalimentam o monitoramento de desempenho), como uma sequência de eventos necessários para uma gestão estratégica orientada para resultados. 
$\mathrm{Na}$ educação, a gestão por resultados se fez sentir a partir do uso de indicadores de desempenho e da avaliação dos sistemas de ensino, das escolas e dos professores (ABRUCIO; SEGATTO, 2017). As pesquisas que abordam os resultados desse modelo de gestão são pouco consensuais, existindo tanto uma literatura detratora (FREITAS, 2004), quanto enaltecedora (GALL; GUEDES, 2009). Em estudo que analisa a reforma educacional orientada por resultados em quatro governos estaduais brasileiros (Espírito Santo, Minas Gerais, Pernambuco e São Paulo), no período de 2007-2010, Abrucio e Segatto (2017, p.85) ressaltam os limites e as nuances desse processo e destacam que ele é menos uniforme do que afirma a literatura existente e que há mais de uma forma de construção e de funcionamento da gestão por resultado na educação.

A fim de apresentar a nova rotina escolar e os instrumentos adotados na reforma educacional na RME/POA, neste estudo foram analisados os seguintes documentos: o Programa de Metas 2017-2020, com os objetivos da gestão municipal para a educação no respectivo período; o decreto 14.521, de 2004, que regulamentava a organização escolar da RME até 2017; as portarias com as Diretrizes Escolares para os anos de 2017 a 2019, que estabeleceram as normas para a nova rotina escolar; bem como leis federais (n. ${ }^{\circ}$ 9394/96 e $\mathrm{n}^{\circ}$ 11.738/08) que norteiam a educação no Brasil, pareceres do Conselho Municipal de Educação de Porto Alegre, ofícios da Associação dos Trabalhadores em Educação do Município de Porto Alegre (ATEMPA) e notícias jornalísticas a respeito da nova rotina escolar.

Por meio da pesquisa documental, com abordagem qualitativa dos dados, realizamos uma análise descritiva comparada das rotinas escolares. De acordo com Collier (1993) a comparação é uma ferramenta de análise fundamental. Mediante a comparação pode-se estabelecer correlações sobre os objetos investigados, podendo se privilegiar tanto as analogias, quanto os contrastes. Desse modo, através da variável temporal, comparamos a organização da rotina escolar da RME/POA, dividida em antes e depois das mudanças implementadas. O período posterior à nova rotina escolar foi dividido em três anos distintos 2017, 2018, 2019 - de acordo com as normativas para cada ano escolar. Com a finalidade de observar o que foi modificado, com vista à aplicação da gestão por resultados na educação, destacamos os seguintes aspectos: horários de entrada e saída escolar, quantidade de minutos da hora-aula, carga horária da disciplina/ professor, reuniões pedagógicas, conselhos de classe, entrega de avaliações e hora-atividade do professor. Os resultados desse levantamento comparativo nos permitiram discutir os instrumentos adotados pela administração municipal e o modo como as mudanças foram propostas e implementadas, buscando averiguar sua correlação com o modelo administrativo que norteou o processo reformista. 


\section{A RME E A NOVA ROTINA ESCOLAR}

A RME/POA é atualmente composta por 99 escolas: 42(quarenta e duas) escolas de Educação Infantil, 53 (cinquenta e três) escolas de Ensino Fundamental, 1 (uma) de Ensino Médio, 1 (uma) Escola de Educação Básica, o Centro Municipal de Educação dos Trabalhadores Paulo Freire e a Escola Porto Alegre. Atende em torno de 50 mil alunos e conta com cerca de 4 mil professores e 900 funcionários (PORTO ALEGRE, 2019b).

No Programa de Metas 2017-2020 (PROMETA) ${ }^{1}$, o governo Marchezan Júnior apresentou para a educação municipal 2 (dois) objetivos estratégicos: aumentar e qualificar a oferta de vagas da educação infantil e melhorar a qualidade do ensino fundamental. Para atingir esses objetivos foram elaboradas 9 (nove) metas estratégicas, que podem ser melhor visualizadas no quadro abaixo:

\section{Quadro 1 - Objetivos e Metas estratégicas da educação (gestão 2017-2020).}

\begin{tabular}{|c|c|}
\hline \multicolumn{2}{|r|}{ EIXO DESENVOLVIMENTO SOCIAL } \\
\hline OBJETIVO ESTRATÉGICO & META ESTRATÉGICA \\
\hline \multirow{2}{*}{$\begin{array}{l}\text { AUMENTAR E QUALIFICAR } \\
\text { A OFERTA DE VAGAS DA } \\
\text { EDUCAÇÃO INFANTIL }\end{array}$} & $\begin{array}{l}\text { META 19: Atender } 100 \% \text { da demanda manifesta para crianças de } 0 \text { a } 3 \text { anos e } 11 \text { meses na } \\
\text { Rede Municipal de Educação. }\end{array}$ \\
\hline & $\begin{array}{l}\text { META 20: Universalizar a Educação Infantil na faixa etária de } 4 \text { a } 5 \text { anos e } 11 \text { meses, } \\
\text { garantindo o atendimento de } 100 \% \text { da demanda na Rede Municipal de Educação Indicador } \\
\text { técnico: Universalização do atendimento às crianças de } 4 \text { a } 5 \text { anos e } 11 \text { meses. }\end{array}$ \\
\hline \multirow{7}{*}{$\begin{array}{l}\text { MELHORAR A QUALIDADE NO } \\
\text { ENSINO FUNDAMENTAL }\end{array}$} & META 21: Obter nota de 5,9 no IDEB 2020 - Anos Iniciais \\
\hline & META 22: Obter nota de 5,3 no IDEB 2020 - Anos Finais \\
\hline & $\begin{array}{c}\text { META 23: Assegurar que } 65 \% \text { dos alunos em anos iniciais das escolas municipais sejam } \\
\text { proficientes em português }\end{array}$ \\
\hline & $\begin{array}{c}\text { META 24: Assegurar que } 60 \% \text { dos alunos em anos iniciais das escolas municipais sejam } \\
\text { proficientes em matemática }\end{array}$ \\
\hline & $\begin{array}{c}\text { META 25: Assegurar que } 50 \% \text { dos alunos em anos finais das escolas municipais sejam } \\
\text { proficientes em português }\end{array}$ \\
\hline & $\begin{array}{c}\text { META 26: Assegurar que 35\% dos alunos em anos finais das escolas municipais sejam } \\
\text { proficientes em matemática }\end{array}$ \\
\hline & $\begin{array}{c}\text { META 27: Garantir o acompanhamento do aprendizado a cada semestre de } 100 \% \text { dos alunos } \\
\text { da Rede Municipal baseado nos descritores da Prova Brasil }\end{array}$ \\
\hline
\end{tabular}

Fonte: PORTO ALEGRE, 2018a.

1 O PROMETA é um programa que contempla os 4 (quatro) anos de gestão municipal e contém as prioridades, os indicadores de desempenho e as metas quantitativas e qualitativas para cada um dos eixos estratégicos de políticas públicas estabelecidas para a administração municipal. Foi incluído por meio de emenda à Lei Orgânica n ${ }^{\circ} 36$, pela Câmara Municipal de Porto Alegre e todo o prefeito eleito tem que apresentar em até 90 dias após a sua posse. O PROMETA 2017-2020 apresentava 16 objetivos estratégicos e 58 metas para diversos setores da administração pública de Porto Alegre, divididos nos seguintes eixos:1. desenvolvimento social; 2. Infraestrutura, economia, serviços e sustentabilidade; 3. Gestão e finanças. (PORTO ALEGRE, 2018a). 
Ao analisar os objetivos e as metas dispostos no PROMETA, podemos perceber que a qualidade do ensino fundamental, objetivo estratégico da gestão 2017-2020, está vinculada ao alcance de metas quantitativas em exames padronizados, no caso o Índice de Desenvolvimento da Educação Básica (IDEB) (AGUIAR, 2019). Essas metas e indicadores foram utilizados a fim de orientar o processo reformista e o baixo desempenho dos alunos municipais foi o argumento para as mudanças que seriam efetuadas a partir de então. Com um discurso de que as mudanças tiveram como foco o aluno e que é inaceitável "atribuir o mau desempenho dos estudantes ao baixo nível social” (MELO, 2019), nesse aspecto guardou semelhanças com a reforma educacional gerencialista efetuada em Nova York - a Children First - a partir de 2002. De acordo com Guedes e Gall (2009, p.6) defensores da aplicação da gestão por resultados na educação, o exemplo da referida cidade

[...] oferece reflexões importantes sobre como mudar o discurso de que crianças pobres com pais sem instrução não podem aprender. A experiência mostra que a escola, o diretor e o professor podem fazer a diferença, desde que recebam apoio e cobrança constantes de um órgão central coeso, ágil e qualificado.

Sem nenhuma consulta prévia à comunidade escolar, poucos dias antes do início do ano letivo, as novas diretrizes de organização da rede escolar foram apresentadas às direções (CANOFRE, 2017). Cabe ressaltar que na RME esse tipo de decisão sempre foi "tomado em cada escola, de acordo com a realidade e necessidades da comunidade escolar, por meio do conselho escolar, em conformidade com a Lei de Diretrizes e Bases e com as condições de recursos humanos e estruturas das escolas" (AGUIAR, 2019, p. 46). A partir dessa reforma administrativa houve, portanto, uma mudança na estrutura organizacional da RME, em que as decisões a respeito do cotidiano escolar passaram a ser verticalizadas: gestores fixando objetivos, elaborando planejamentos estratégicos, táticos e operacionais a serem executados, sem questionamentos, por seus colaboradores. Embora no passado a gestão por resultados tenha se caracterizado pelo autoritarismo, de acordo com Chiavenato (2012, p.28) hoje ela tem uma abordagem democrática e participativa, servindo de "base para os novos esquemas de avaliação do desempenho humano, remuneração flexível e, sobretudo, para a compatibilização entre os objetivos organizacionais e os objetivos individuais das pessoas". Neste sentido, a condução da administração municipal, na implementação da reforma educacional na RME, contrariou os pressupostos do próprio modelo administrativo norteador do processo reformista, uma vez que ele prevê gestores e subordinados identificando objetivos comuns e definindo as 
áreas de responsabilidade de cada um em termos de resultados esperados, que então "passam a constituir os indicadores ou padrões de desempenho sob os quais ambos serão avaliados" (CHIAVENATO, 2012, p.228).

Apesar disso, a nova rotina escolar foi o primeiro passo adotado nesse processo reformista com vistas à aplicação da gestão por resultados na educação da administração Marchezan Júnior. Até essa data, a organização do cotidiano escolar era regulamentada pelo decreto 14.521, de 2004. O documento estabelecia que a hora-aula era o "período de tempo equivalente a 50 (cinquenta) minutos, em que o professor desempenha atividades docentes diretamente com aluno, em turma, em grupos ou individualmente". Em seu artigo $3^{\circ}$ estipulava a distribuição do regime de trabalho do professor, correspondente a 20 (vinte) horas semanais em:

I - 15 (quinze) horas aula;

II - o restante de seu regime de trabalho será de horas-atividade, assim distribuídas:

a) 02 (duas) horas de atividades individuais de planejamento;

b) 05 (cinco) horas e 30 (trinta) minutos de atividades coletivas de formação e planejamento em serviço (PORTO ALEGRE, 2004).

As escolas de ensino fundamental e médio atendiam aos alunos de segunda a sexta-feira, 4 horas e 30 minutos diários. Excetuavam-se às quintasfeiras, quando tinham 2 horas e 30 minutos de aula, sendo os alunos depois dispensados, para que os professores pudessem realizar 1 hora e 30 minutos de reunião pedagógica semanal. Da carga horária de trabalho dos professores de 20 horas semanais, eram cumpridas 18 horas presenciais (em 4 dias de 4 horas e 30 minutos) e 2 horas de atividades individuais de planejamento à distância, em dia de trabalho denominado de "compensação".

Com a proposição da nova rotina escolar, estabelecida nas Diretrizes para o Calendário Escolar de 2017, constantes na Portaria 135/17, as aulas passaram para "4 (quatro) horas diárias distribuídas em 5 (cinco) períodos de 45 (quarenta e cinco) minutos, incluindo o recreio de quinze minutos" (PORTO ALEGRE, 2017a), nos 5 dias de semana. Em Memorando Circular N3/2017, a Diretoria Pedagógica da SMED, "com fins de contribuir para a compreensão" das referidas diretrizes ainda esclarecia que: 
cada professor deve trabalhar dezessete períodos em atividades diretas com os alunos, totalizando 12 horas e 45 minutos (para um docente de 20 horas e nesta proporção para os demais contratos) e terá 7 horas e 15 minutos para atividades extra-aula, ou seja, atividades de estudo, planejamento e avaliação (individual e coletiva). Não tem compensação. A atividade de planejamento individual deverá estar prevista no calendário escolar anual e poderá ser feita em ambiente escolar ou, a critério, justificado da escola, fora dele (PORTO ALEGRE, 2017b).

Podemos perceber que a primeira grande mudança proposta pela nova rotina escolar foi na questão dos tempos das escolas (tempos de aprendizagem e tempos de trabalho): horários de entrada e saída da escola, duração dos períodos, organização da carga horária dos professores. $\mathrm{Na}$ antiga rotina, embora fossem dispensados mais cedo às quintas-feiras, ao longo da semana os alunos tinham 20 horas e 30 minutos de aula; enquanto na nova rotina escolar, a carga horária semanal passou para 20 horas, diminuindo em 30 minutos a permanência dos alunos na escola. A quantidade de minutos da hora-aula também sofreu alteração, diminuindo-se em 5 minutos cada período. Por outro lado, o tanto de períodos a serem dados pelo professor passou de 15 para 17, aumentando em 15 minutos a carga horária docente em atividades diretas em sala de aula, como pode ser visualizado no quadro abaixo:

\section{Quadro 2 - Quadro comparativo antes e depois da nova rotina escolar}

\begin{tabular}{|c|c|c|c|c|}
\hline \multirow{2}{*}{} & \multirow{2}{*}{ ANTES } & \multicolumn{4}{c|}{ DEPOIS } \\
\cline { 3 - 5 } & & 2017 & 2018 & 2019 \\
\hline ENTRADA & $7: 30 / 13: 00$ & 2017 & 2018 & 2019 \\
\hline SAÍDA & $12: 00 / 17: 30^{2}$ & $8: 00 / 13: 30$ & $8: 00 / 13: 30$ & $8: 00 / 13: 30$ \\
\hline HORA AULA & 50 min & $12: 00 / 17: 30$ & $12: 00 / 17: 30$ & $12: 00 / 17: 30$ \\
\hline PERÍODO/PROFESSOR & 15 & 45 min & 45 min & 45 min \\
\hline REUNIÕES PEDAGÓGICAS & $\begin{array}{c}\text { Dentro da carga horária } \\
\text { semanal }\end{array}$ & 17 & 17 & 17 \\
\hline 1 hora 30 min (HADE) & & - & 16 hs/ano (sábado) & 32 hs/ano (sábado) \\
\hline CONSELHO DE CLASSE & $\begin{array}{c}\text { Dentro da carga horária } \\
\text { semanal }\end{array}$ & $\begin{array}{c}\text { Fora da carga horária semanal } \\
\text { (sábados/vespertino) }\end{array}$ & $\begin{array}{c}\text { Fora da carga horária } \\
\text { semanal (sábados/ } \\
\text { vespertino) }\end{array}$ & $\begin{array}{c}\text { Fora da carga horária } \\
\text { semanal (sábados/ } \\
\text { vespertino) }\end{array}$ \\
\hline ENTREGA DE AVALIAÇÕES & $\begin{array}{c}\text { Dentro da carga horária } \\
\text { semanal (HADE) }\end{array}$ & $\begin{array}{c}\text { Fora da carga horária semanal } \\
\text { (sábados/vespertino) }\end{array}$ & $\begin{array}{c}\text { Fora da carga horária } \\
\text { semanal (sábados/ } \\
\text { vespertino) }\end{array}$ & $\begin{array}{c}\text { Fora da carga horária } \\
\text { semanal (sábados/ } \\
\text { vespertino) }\end{array}$ \\
\hline HAFE & 2 horas & 4 horas & 0 horas & 0 horas \\
\hline HADE & 5 horas 30 min & 3 horas 15 min & 7 horas 15 min & 7 horas 15 min \\
\hline
\end{tabular}

Fonte: PORTO ALEGRE, 2004; PORTO ALEGRE, 2017 a; PORTO ALEGRE, 2018; PORTO ALEGRE, 2019d.

2 Exceto às $5^{\mathrm{a}}$ feiras, quando os alunos tinham 2 horas e 30 minutos e após eram dispensados para que houvesse a realização de reunião pedagógica dos professores.

1242 - Rev. Bras. Polít. Adm. Educ. - v. 37, n. 3, p. 1235 - 1254, set./dez. 2021 
Essa reconfiguração da carga horária docente teve um efeito direto na alocação dos recursos humanos das unidades escolares, pois cada professor passou a atender um número maior de turmas e de alunos. Tal medida se traduziu em uma otimização do capital humano (professores) atuantes nas escolas a partir da nova rotina escolar. Fazer o mesmo trabalho, com menos professores, aumentando sua carga horária de trabalho em atendimento direto aos alunos, a fim de reduzir a folha de pagamento da SMED. Tanto é que, em apresentação realizada na Comissão de Economia, Finanças, Orçamento e do MERCOSUL (Cefor), da Câmara Municipal de Porto Alegre, em dezembro de 2018, o secretário da educação Adriano Naves de Britto destacou que "é no gasto com pessoal que está a maior fatia do orçamento da pasta" e que esta apresentou uma "redução de quase dois pontos percentuais entre 2016, quando consumiu $71,87 \%$ dos recursos, para os 69,9\% alcançados em 2018” (PORTO ALEGRE, 2019).

Em virtudes das mudanças trazidas pela nova rotina escolar - sobretudo no que tange à organização da carga horária dos professores e os tempos das escolas da RME, especificamente as de Ensino Fundamental e Médio, que provoca consequências nos Calendários Escolares e nos Quadros de Recursos Humanos - a ATEMPA encaminhou uma consulta ao Conselho Municipal de Educação de Porto Alegre (CME/POA), questionando a Portaria 135/2017, pois ela demonstrou "pela sua forma, apresentação e concepção, [...] desrespeito frontal com as comunidades escolares e, precisamente, com suas propostas políticopedagógicas, que é quem organiza os espaços e tempos da Escola". (ATEMPA, 2017 apud PORTO ALEGRE, 2017e, p.2). Em resposta, em seu parecer n. ${ }^{\circ}$ 001/2017, o CME/POA sublinhou que era "prerrogativa do gestor propor mudanças a fim de qualificar o currículo escolar, mas estas devem passar por discussões coletivas, diagnósticos participativos, acordos solidários e assentados nos princípios do Sistema Municipal de Ensino" (PORTO ALEGRE, 2017e, p. 25).

Há de se destacar que as novas diretrizes para a organização das escolas municipais foram comunicadas pelo secretário da educação Adriano Naves de Brito às direções escolares em fevereiro de 2017. Em assembleia geral, realizada em 03 de março, os trabalhadores em educação decidiram pelo descumprimento do que se passou a chamar de nova rotina escolar. O ano letivo iniciou em 06 de março de 2017, com as escolas mantendo a rotina da gestão anterior. Foram meses de discussões que envolveram o Sindicato dos Municipários de Porto Alegre (Simpa), Associação dos Trabalhadores em Educação do Município de Porto Alegre (Atempa), Conselho Municipal de Educação (CME), Promotoria da Infância e da Juventude, assembleias de professores, e desencadearam diversos protestos e manifestações. No início de maio, apenas 11 escolas haviam aderido 
à nova rotina escolar e ameaças de corte de ponto dos professores que não aderissem às mudanças foram feitas pelo secretário da educação (CHAGAS, 2017; PROFESSORES, 2017a; PROFESSORES, 2017b).

Entendendo gestão de pessoas como um processo, uma relação "que envolve múltiplos atores, em todos os níveis e áreas da organização", tanto gestores, quanto cada membro da equipe são "coprodutores dos resultados; todos são responsáveis, seja pela qualidade da relação, seja pelo resultado do trabalho, ou pela saúde do ambiente, enfim" (BERGE, 2019, p.13). Porém, cabe ao gestor e a seu papel de liderança compreender os mecanismos de ativação da motivação das pessoas, de impulso para a ação, a fim de que elas promovam as entregas de resultados (BERGE, 2019). É neste sentido que se questiona a maneira como foram propostas as mudanças para a educação em Porto Alegre, haja vista os professores municipais mostrarem um descontentamento com a "falta de diálogo na construção de uma nova política educacional", uma vez que "foram apenas comunicados sobre a revogação de um decreto e a implementação de um novo programa" (CANOFRE, 2017). Ao invés de despertar a motivação dos educadores para aderirem às mudanças propostas, a fim de entregar os resultados projetados pela gestão municipal, o que se pode observar é que o processo reformista encontrou forte resistência por parte dos trabalhadores em educação e da comunidade escolar como um todo.

Outra alteração significativa nos tempos escolares, promovida pela nova rotina escolar, foi em relação às reuniões pedagógicas. Embora as Diretrizes para o Calendário Escolar de 2017 façam menção a elas, devendo ocorrer "semanalmente, às quintas-feiras, com a duração de 90 (noventa) minutos em cada turno de trabalho" e que "nos dias de Reunião Pedagógica os alunos são atendidos com carga horária integral, no seu turno" (PORTO ALEGRE, 2017a), o documento não esclarece como seria feito esse atendimento, haja vista os docentes estarem em reunião pedagógica durante esse período. Na prática, a nova rotina escolar levou à supressão das reuniões pedagógicas na RME.

A fim de contemplar essa dificuldade, as diretrizes para o Calendário Escolar 2018 autorizavam as escolas a "planejar até 4 (quatro) sábados, de 4 (quatro) horas, por ano, para reunião de estudos com todo o grupo de cada unidade escolar". Os Conselhos de Classe também foram transferidos para os sábados, estando as escolas "autorizadas a planejar 1 (um) sábado por trimestre [...] por no máximo 4 (quatro horas)"; bem como entregas de avaliações, que por necessitar "tempo de reunião com as famílias, sem prejudicar o atendimento aos alunos", deve ocorrer no "turno vespertino, por no máximo 2 (duas) horas 
ou concomitantemente com um dos sábados em que esteja prevista reunião de estudos dos profissionais da escola, por no máximo 4 (quatro) horas, não sendo o dia computado como letivo" (PORTO ALEGRE, 2018).

Para o ano de 2019 as diretrizes para a elaboração dos calendários escolares estabeleceu em seu art. 8 que

[...] as EMEF, EMEB e EMEM devem deslocar 4 (quatro) horas da hora atividade do planejamento do professor e da carga horária dos setores, em cada mês, para os sábados 13 de abril, 18 de maio, 15 de junho, 20 de julho, 18 de agosto, 14 de setembro, 19 de outubro e 23 de novembro, com objetivo de garantir que o grupo de professores se reúna para deliberações gerais, sem prejuízo ao atendimento dos alunos e funcionamento da escola (PORTO ALEGRE, 2019 d).

Da mesma maneira autorizou as escolas "a planejar 1 (um) sábado por trimestre para realização de Conselhos de Classe, por no máximo 4 (quatro) horas" e a realizar a entrega de avaliações em reunião, aos moldes do ano anterior (PORTO ALEGRE, 2019 d).

A partir dessas diretrizes se passou a exigir o cumprimento de uma jornada laboral extra, a ser realizada aos sábados ou no vespertino, a fim de que se desempenhassem as obrigações cabíveis a cada unidade escolar. Até a nova rotina escolar, tais atividades eram realizadas dentro da carga horária semanal de cada trabalhador. Desse modo, verifica-se que a nova rotina escolar, ao modificar os tempos de trabalho dos professores, acarretou numa intensificação do trabalho docente $^{3}$. É nesse sentido que Melchior (2008 apud ASSUNÇÃO; OLIVEIRA, 2009) destaca que mudanças organizacionais no bojo da evolução dos sistemas e de suas reformas podem gerar mecanismos de intensificação do trabalho, sendo isso uma das causas do "mal-estar docente" verificado atualmente (ESTEVE, $1999)^{4}$.

Outro ponto a ser destacado nas mudanças propostas pela nova rotina escolar é o que sistematiza o tempo dos professores destinados a atividades extraclasse. A Lei de Diretrizes e Bases da Educação Nacional (BRASIL, 1996),

\footnotetext{
3 Por intensificação do trabalho docente entendemos o aumento de gasto de energias dos professores e professoras para a realização de suas atividades laborais, quando se passa a ser exigido um empenho maior, seja físico (corpo), intelectual (acuidade mente/saberes) ou psíquico (emocional/afetividade), ou uma combinação desses elementos, e que pode ser percebido através de fatores quantitativos, relacionados ao aumento do volume de tarefas nas escolas; e qualitativos, relacionados às circunstâncias sob as quais os docentes mobilizam as suas capacidades físicas, cognitivas e afetivas para atingir os objetivos da produção escolar (DAL ROSSO, 2008; ASSUNÇÃO; OLIVEIRA, 2009).

4 "Essa expressão tem sido usada para designar os efeitos permanentes de caráter negativo que afetam a personalidade do professor, como resultado das condições psicológicas e sociais em que se exerce a docência. É, portanto o termo que tem nomeado o complexo processo no qual professores expressam suas marcas subjetivas e corporais produzidas no processo de trabalho, suportado a custa de desgaste e sofrimento" (ESTEVE, 1999, p. 39).
} 
lei $\mathrm{n}^{\circ} 9.394$ de 20 de Dezembro de 1996, que estabelece as diretrizes e bases da educação nacional, em seu artigo 37 , inciso $\mathrm{V}$ assegura "período reservado a estudos, planejamento e avaliação, incluído na carga de trabalho"; bem como a Lei Federal n ${ }^{\circ} 11.738$, de 2008 (BRASIL, 2008), que instituiu o piso salarial profissional nacional para os profissionais do magistério público da educação básica determinou em seu artigo 2o., parágrafo $4^{\circ}$, que "na composição da jornada de trabalho, observar-se-á o limite máximo de $2 / 3$ (dois terços) da carga horária para o desempenho das atividades de interação com os educandos". Dessa maneira, o terço restante da jornada do professor deve ser obrigatoriamente reservado para a realização de atividades extraclasse, como o planejamento pedagógico.

$\mathrm{Na}$ antiga rotina esse tempo estava distribuído em 02 horas de atividades individuais de planejamento - que poderiam ser executadas fora do espaço escolar - e 05 horas e 30 minutos de atividades coletivas de formação e planejamento em serviço. A partir da nova rotina, o tempo destinado às atividades extra-aula (estudo, planejamento e avaliação) passou para 7 horas e 15 minutos. No primeiro ano de implantação das mudanças, era permitido que 4 horas dessa atividade fossem realizadas em ambiente escolar ou fora dele, a critério da escola - HAFE (hora-atividade fora da escola) ou HADE (hora-atividade dentro da escola). No ano seguinte, porém, o portal Gaúcha/ $Z H^{5}$ noticiava que a prefeitura havia intensificado "as mudanças adotadas a partir do ano passado com a reorganização das atividades das instituições de ensino", ao enviar um comunicado para as direções das escolas, na sexta-feira, 09 de fevereiro de 2018, "sobre o fim da hora-atividade fora da escola" (CHAGAS, 2018). Tal medida, de acordo com o secretário da educação, estava prevista desde a reorganização da rotina escolar; porém, não havia se concretizado por falta de um controle efetivo da jornada de trabalho dos professores, o que fez com que a secretaria mantivesse a prática ao longo do ano.

Ao constatar a inadequação do espaço escolar para que professores realizem as atividades extraclasse na escola, podemos afirmar que retirada da HAFE é outro fator que levou à intensificação do trabalho docente. Sem computadores ou salas para seu trabalho, por exemplo, muitos "ficam um turno inteiro na sala dos professores para cumprir horário determinado e após realizam seu planejamento na estrutura de sua residência” (FRAGA, 2018, p.9).

5

O portal Gaúcha/ ZH (Porto Alegre/RS) é uma plataforma de notícias produzidas pelas equipes do jornal impresso Zero Hora e da Rádio Gaúcha. Surgida em 2017, trata-se da mescla da atuação de ambos os veículos. Anteriormente essa produção ocorria em separado, em Zero Hora.com e na página da Rádio Gaúcha. Ambos os veículos são vinculados ao Grupo RBS (BELOCHIO, 2018). 
Como mencionamos anteriormente, desde o anúncio das referidas mudanças na rotina escolar, um forte tensionamento se estabeleceu entre os trabalhadores da educação e os gestores municipais. Foram meses de discussões entre os segmentos até a adequação das escolas ao novo modelo. Como estratégia para a resolução do impasse, a gestão municipal passou a negociar em particular com cada uma das direções escolares. A permissão da secretaria para que os professores realizassem 4 horas de planejamento individual fora da escola foi utilizada como mecanismo de convencimento para adesão à nova rotina nas negociações efetivadas com cada uma das escolas em particular (BENFICA, 2017; CHAGAS, 2017).

A adoção de metas e indicadores que serviram para nortear as políticas públicas e mecanismos de contratualização, a partir dos quais os atores envolvidos seriam cobrados, premiados, punidos, são características comuns a experiências brasileiras na aplicação da gestão por resultados na educação (ABRUCIO; SEGATTO, 2017). A partir disso, podemos entender a supressão da HAFE, no ano seguinte à implantação da nova rotina escolar, como um instrumento punitivo da gestão municipal, haja vista os professores terem apresentado resistência às mudanças propostas, não se alinhando às táticas da nova gestão. Note-se que o final do ano de 2017 foi marcado pela maior greve da história dos municipários de Porto Alegre, sendo a categoria professor a de maior representatividade numérica nos quadros funcionais da Prefeitura de Porto Alegre ${ }^{6}$.

Em Ofício no 031/2018, enviado à SMED, a ATEMPA “na condição de representante dos (as) trabalhadores (as) da Rede Municipal de EnsinoRME", questionou as normativas para o ano de 2018 que concediam "a HORA ATIVIDADE FORA DA ESCOLA apenas para professores que estão 40h na mesma escola, em regência, nos turnos manhã e tarde" (ATEMPA, 2018), destacando que, além de promover o tratamento desigual aos profissionais da educação, a medida dificultava o planejamento de quem precisava fazê-lo na escola, pois nelas não existem condições efetivas para essas atividades. Além de questionar a SMED em relação à referida Portaria (n.o 024/2018), a ATEMPA consultou o Conselho Municipal de Educação (CME). Em resposta, em seu parecer, o CME indicou o diálogo entre os agentes (gestores e trabalhadores) como caminho para a resolução do impasse (PORTO ALEGRE, 2018c).

As distintas trajetórias das reformas na política de educação nos estados analisados por Abrucio e Segatto (2017, p.102-103) - Espírito Santo, Minas Gerais, Pernambuco e São Paulo -, por sua vez, foram resultados das seguintes variáveis: "da realização de reformas anteriores, da inspiração para a adoção da

6 Em dezembro de 2017, a PMPA possuía 25.714 servidores (entre ativos e inativos). Destes, 4.898 servidores estavam vinculados à SMED (PORTO ALEGRE, 2017 d). 
reforma, da situação administrativa das secretarias estaduais de educação e das redes estaduais de ensino, além do modo como as medidas foram implementadas e negociadas com a burocracia e os sindicatos". Apontam como a principal fraqueza das reformas analisadas o fato de ela não ter sido amplamente discutida com a "sociedade civil somente o foi, em alguns casos, com os sindicatos de professores". O mesmo equívoco também foi cometido na reforma educacional que está sendo levada a cabo em Porto Alegre.

Um dos fundamentos da gestão por resultados está no comprometimento de toda a equipe com as metas da organização. Abrucio e Segatto (2017, p.88) destacam que a atuação de determinados dirigentes públicos e o apoio da burocracia pública foram importantes no processo reformista gerencial da educação brasileira efetuada a partir da década de 1990. De acordo com os autores, os primeiros (dirigentes públicos) influenciaram a entrada desse assunto na agenda governamental. E os segundos (burocracia pública) conferiram aceitação e legitimidade a esses instrumentos. É neste sentido que professores tornam-se peça essencial no sucesso da implementação do modelo. Sua adesão às mudanças propostas é vital, pois caso contrário, pode ocorrer o fenômeno conhecido como o gaming,

[...] que, na educação, pode resultar, por exemplo, no controle intencional do desempenho pelos professores ou gestores escolares para que as metas futuras não sejam aumentadas; na exclusão da avaliação de alunos que não alcançam o nível adequado; e na ênfase excessiva aos conteúdos e disciplinas que são avaliados (ABRUCIO; SEGATTO, 2017, p.80).

À vista disso, a Prova Brasil de 2017, avaliação diagnóstica da qualidade de ensino oferecido pelo sistema educacional brasileiro que, ao lado das taxas de aprovação, subsidiam o cálculo do IDEB, foi aplicada em 8 das 56 escolas de ensino fundamental da RME. Boicotada pela greve de 41 dias dos servidores municipais de Porto Alegre (sendo a categoria professores a imensa maioria), não teve seu resultado divulgado por não ser considerado significativo (AGUIAR, 2019). Vale aqui lembrar que a gestão por resultados tem como objetivo a criação de valor público ao se atingir os resultados estipulados nos objetivos dos programas de governo, e que aumentar os índices de desempenho no IDEB dos alunos da RME estava entre as metas estratégicas da gestão municipal 2017-2020. Nos anos iniciais a meta era obter nota de 5,9 no IDEB 2020; porém, obteve 4,9. Nos anos finais, a meta de 5,3 não foi alcançada, ficando 1,6 pontos abaixo do projetado e regredindo 0,1 ponto quando comparado ao IDEB 2015 (PROMETA 2017 2020, 2017; BRASIL, 2020). 


\section{CONSIDERAÇÕES FINAIS}

Ao longo deste artigo foi possível verificar que a nova rotina escolar foi o primeiro passo dado no processo reformista educacional do município de Porto Alegre, orientado pela aplicação da gestão por resultados na educação. A adoção da reforma foi justificada pelo baixo desempenho dos alunos nas avaliações e o alcance de metas e indicadores pautaram o processo reformista. Com um discurso de que as mudanças tinham como foco o aluno e seu aprendizado, as decisões foram tomadas de maneira verticalizada e levaram a uma reorganização dos horários das escolas de RME/POA.

Desta forma, as mudanças propostas pela nova rotina alteraram, sobretudo, os tempos escolares - tempos de aprendizagem e tempos de trabalho. Ao visar a otimização dos recursos humanos a fim de reduzir custos com a folha de pagamento do município, promoveu um aumento de volume das atividades a serem desempenhadas pelos professores e serviu como mecanismo de punição a não adesão às táticas estabelecidas pela nova gestão. Tais medidas além de gerar uma intensificação do trabalho docente, com possíveis efeitos sobre sua saúde, suscitaram uma profunda tensão entre a gestão municipal e o corpo docente da RME. Embora o processo reformista tenha sido efetuado com foco na obtenção de resultados de desempenho educacionais, no plano operacional pautou-se por modelos tradicionais de administração, ignorando os processos de ativação de motivações dos colaboradores como um dos componentes essenciais para a obtenção dos resultados pretendidos pela organização. Conclui-se, portanto, que a intervenção efetuada na realidade escolar, através da nova rotina e dos instrumentos adotados pela administração municipal no processo reformista, com vistas à aplicação da gestão de resultados na educação, ao não atingir os resultados estipulados nos objetivos do próprio programa de governo 2017-2020, não se traduziu em efetividade e criação de valor público, como sugere o modelo administrativo em questão. 


\section{REFERÊNCIAS}

ABRUCIO, Fernando; SEGATTO, Catarina. A gestão por resultados na educação em quatro estados brasileiros. Rev. Serv. Público, Brasília 68 (1) 85-106 jan/mar 2017.

AGUIAR, Felipe de. Políticas educacionais na Rede Municipal de Ensino de Porto Alegre: impactos sobre o trabalho docente na gestão 2017-2020. Dissertação (mestrado), Programa de Pós Graduação em Educação, Universidade Federal do Rio Grande do Sul, Porto Alegre, 2019.

; SANTOS, Graziella. Reorientações gerencialistas das políticas educacionais: impactos na rede municipal de ensino de Porto Alegre. Políticas Educativas, Santa Maria, v. 12, n. 1, p. 73-92, 2018.

ASSOCIAÇÃO DOS TRABALHADORES/AS EM EDUCAÇÃO DO MUNICÍPIO DE PORTO ALEGRE. Ofício $\mathbf{n}^{\mathbf{0}}$ 031/2018. Porto Alegre, RS, 2018. Disponível em https://atempa.org.br/atempa-entrega-documento-sobrea-rede-a-smed/. Acesso em 01 de jan. de 2020.

BELOCHIO, Vivian. Características do webjornalismo contemporâneo em Gaúcha ZH: transformações da plataforma jornalística. In: Anais do $16^{\circ}$ Encontro Nacional de Pesquisadores em Jornalismo FIAM-FAAM / Anhembi Morumbi, São Paulo, 2018. Disponível em https:/ / www.researchgate.net/profile/ Vivian_Belochio2/publication/328890778_Caracteristicas_do_webjornalismo_ contemporaneo_em_Gaucha_ZH_transformacoes_da_plataforma_jornalistica/ links/5be9ea53299bf1124fce1a6c/Caracteristicas-do-webjornalismocontemporaneo-em-Gaucha-ZH-transformacoes-da-plataforma-jornalistica.pdf. Acesso em 28 de abr. de 2020.

BRASIL. Casa Civil. Lei $\mathbf{n}^{\mathbf{0}} \mathbf{1 1 . 7 3 8 / 2 0 0 8}$. Disponível em http://www.planalto. gov.br/ccivil_03/_ato2007-2010/2008/lei/111738.htm. Acesso em 01 de jan. de 2020.

Lei $\mathrm{n}^{\circ}$ 8.080, de 19 de setembro de 1990. Lei Orgânica da Saúde. Brasília, set. 1990. Disponível em <http://conselho.saude.gov.br/legislacao/ lei8080_190990.htm>. Acesso em 15 de nov. de 2019. 
CANOFRE, F. Entenda o que dizem professores e Secretaria de Educação sobre mudanças na rede de Porto Alegre, Sul21, 2017. Disponível em https://bit. ly/2ELCQs . Acesso em 1 jun. 2019.

CHAGAS, Ângela. Prefeitura muda norma que permitia a professores trabalharem de casa. GAÚCHA/ZH, 09 de fev. de 2018. Disponível em https://gauchazh. clicrbs.com.br/porto-alegre/noticia/2018/02/prefeitura-muda-norma-quepermitia-a-professores-trabalharem-de-casa-cjdg20hfy00fb01n3b3eeytid.html. Acesso em 01 de jan. de 2020.

- Com pouca adesão a novas regras em escolas, prefeitura diz que vai cortar ponto de professores. GAÚCHA/ZH, 04 de maio de 2017. Disponível em https://gauchazh.clicrbs.com.br/porto-alegre/noticia/2017/05/compouca-adesao-a-novas-regras-em-escolas-prefeitura-diz-que-vai-cortar-ponto-deprofessores-9786192.html. Acesso em 26 de abr. de 2020.

CHIAVEnato, Idalberto. Princípios da Administração - O essencial em Teoria Gerald a Administração. Manole: São Paulo, 2012.

COLLIER, D. The Comparative Method. In.: Ad W. Finifter, ed. Political Science, The State of the Discipline II. Washington, D.C., American Political Science Association, 1993.

ESTEVE, José M. Mal-estar docente: a sala de aula e a saúde do professor. Bauru, São Paulo: EDUSC, 1999.

FACCIN, Milton Julia. Zero Hora, a voz que une os gaúchos. In: Anais do VII Encontro Nacional de História da Mídia, Fortaleza, 2009.

FREITAS, L. C. de. A avaliação e as reformas dos anos de 1990: novas formas de exclusão, velhas formas de subordinação. Educação \& Sociedade, v. 25, n. 86, 2013.

GALL, N.; GUEDES, P. M. A reforma educacional de Nova York: possibilidades para o Brasil. São Paulo: Fundação Itaú Social e Instituto Fernand Braudel de Economia Mundial, 2009.

MATIAS-PEREIRA, J. Manual da gestão pública contemporânea. 2.ed. São Paulo: Atlas, 2009. 
MELO, I. Com professores mais bem pagos entre as capitais, Porto Alegre tem ensino mal avaliado em provas. GaúchaZH, 2019. Disponível em https://bit. ly/2EWc3t. Acesso em 28 nov. 2019.

PORTO ALEGRE, Prefeitura Municipal de. Decreto 14.521/04. 2004. Disponível em http://www2.portoalegre.rs.gov.br/cgi-bin/nph-brs?s1=000026201. DOCN. $\& \mathrm{l}=20 \& \mathrm{u}=/$ netahtml $/$ sirel $/$ simples.html $\& \mathrm{p}=1 \& \mathrm{r}=1 \& \mathrm{f}=\mathrm{G} \& \mathrm{~d}=$ atos $\& \mathrm{~S}$ ECT1=TEXT. Acesso em 01 de jan. de 2020.

Secretaria Municipal de Educação. Portaria 135/17. 2017a. Disponível emhttp://dopaonlineupload.procempa.com.br/dopaonlineupload/3068_ ce_20191017_executivo.pdf. Acessado em 20 de jan. de 2020.

Secretaria Municipal de Educação. Memorando Circular N3/2017. 2017b. Acervo particular.

Programa de Metas 2017-2020. Prefeitura Municipal de Porto Alegre. Porto Alegre, 2018a. Disponível em http://lproweb.procempa.com.br/pmpa/ prefpoa/smpeo/usu_doc/prometa_poa_2017-2020.pdf. Acesso em 30 de mar. de 2020 .

Secretaria de Educação. Secretário de Educação debate a nova rotina escolar na CMPA. Porto Alegre, 01 de Mar. de 2017. 2017 c. Disponível em http://www2.portoalegre.rs.gov.br/smed/default.php?p_noticia=191702\&S ECRETARIO+DE+EDUCACAO+DEBATE+A+NOVA+ROTINA+ESCO LAR+NA+CMPA. Acesso em 25 de jul. de 2019.

Secretaria Municipal de Educação. Quadro síntese - servidores municipais, dezembro de 2017. 2017d. Disponível em http://proweb. procempa.com.br/pmpa/prefpoa/transparencia/usu_doc/cargos_quadro_ sintese_122017.pdf. Acesso em 18 de jan. de 2020.

. Conselho Municipal de Educação. Parecer CME/PoA n. ${ }^{\circ}$ 001/2017, 2017 e. Disponível em https://websmed.portoalegre.rs.gov.br/escolas/cme/ pareceres_2017.htm. Acesso em 02 de jan. de 2020. 
. Secretaria municipal de Educação. Portaria 024/2018, 2018b. Disponível em http://www2.portoalegre.rs.gov.br/netahtml/sirel/atos/Portaria\%20 024\%202018\%20SMED\%20retificada. Acesso em 01 de jan. de 2020.

. Conselho Municipal de Educação. Parecer CME/PoA n. ${ }^{\circ}$ 007/2018, 2018 c. Disponível em https://websmed.portoalegre.rs.gov.br/escolas/cme/ pareceres_2017.htm. Acesso em 02 de jan. de 2020.

. Secretaria Municipal da Educação, 2019ª Disponível em https:// prefeitura.poa.br/smed. Acesso em 29 de dez. de 2019.

. Secretaria Municipal da Educação. Relação de Escolas - Escolas Municipais, 2019b. Disponível em https://dadosabertos.poa.br/dataset/sie. Acesso em 19 de dez. de 2019.

. Secretaria municipal de Educação. Portaria 01/2019, 2019d. Disponível em http://dopaonlineupload.procempa.com.br/dopaonlineupload/2739_ ce_20190109_executivo.pdf. Acesso em 01 de jan. de 2020.

. Câmara Municipal. Smed fará prova censitária com alunos da rede municipal em 2019, 2019e. Disponível em www.camarapoa.rs.gov.br/noticias/ smed-fara-prova-censitaria-com-alunos-da-rede-municipal-em-2019. Acesso em 24 de dez. de 2019.

. Câmara Municipal. Projeto de Lei 020/19, 2019 f. Disponível em http:// camarapoa.rs.gov.br/processos/135558. Acesso em 31 de jan. de 2020.

PROFESSORES protestam na Câmara de Porto Alegre contra mudanças. G1, 02 de mar. de 2017 (2017a). Disponível em http://g1.globo.com/rs/rio-grande-do$\mathrm{sul} /$ noticia/2017/03/professores-protestam-contra-mudancas-na-camara-deporto-alegre.html. Acesso: em 26 de abr. de 2020.

PROFESSORES de Porto Alegre decidem rejeitar mudanças na carga horária. G1, 03 de mar. de 2017 (2017b). Disponível em http://g1.globo.com/rs/riogrande-do-sul/noticia/2017/03/professores-de-porto-alegre-decidem-rejeitarmudancas-na-carga-horaria.html. Acesso em 28 de abr. de 2020. 
PROGRAMA de Governo: Candidatura Nelson Marchezan PSDB / Porto Alegre: Eleições 2016. Porto Alegre: PSDB, 2016. Disponível em: file:///C:/ Users/daniel-magnus/Downloads/proposta_governo1471291722755\%20(1). pdf. Acesso em: 30 out. 2019.

ROSA, Antonio Lisboa et al. O Marco Lógico da Gestão Pública por Resultados (GPR). In:.

SERRA, A. Modelo aberto de gestão de resultados no setor público. Natal: SEARH/RN, 2008.

SOUZA, Allan Solano; CABRAL NETO Antônio. A nova gestão pública em educação. Planejamento estratégico como instrumento de responsabilização. Revista Retratos da Escola, Brasília, v. 11, n. 21, p. 621-640, jul./dez. 2017. Disponível em: http//www.esforce.org.br, acesso em 25 de jul. de 2019.

\section{Caroline Pereira Leal}

É doutora em História (PUCRS) e especialista em Gestão Pública (UERGS). Atua como professora na RME/POA desde 2012. E-mail: carolpleal@yahoo. com.br 